\title{
A systematic review of the clinical survival of zirconia implants
}

\author{
Dena Hashim $^{1}$ - Norbert Cionca ${ }^{1}$ - Delphine S. Courvoisier ${ }^{2} \cdot$ Andrea Mombelli $^{1}$
}

Received: 29 February 2016 / Accepted: 6 May 2016/Published online: 24 May 2016

(C) The Author(s) 2016. This article is published with open access at Springerlink.com

\begin{abstract}
Objectives The aim of this review was to evaluate the clinical success and survival rates of zirconia ceramic implants after at least 1 year of function and to assess if there is sufficient evidence to justify using them as alternatives to titanium implants.

Materials and methods An electronic search in MEDLINE, EMBASE, and the Cochrane Central Register of Controlled Clinical Trials (CENTRAL) databases was performed in April 2015 by two independent examiners to retrieve clinical studies focusing on the survival rate of zirconia implants after at least 1 year of function. Implant survival was estimated using the overall proportion reported in the studies with a ClopperPearson $95 \%$ confidence interval (random effect model with a Der-Simonian Laird estimate).

Results Fourteen articles were selected out of the 1519 titles initially screened. The overall survival rate of zirconia oneand two-piece implants was calculated at $92 \%$ (95\% CI 87-95) after 1 year of function. The survival of implants at 1 year for the selected studies revealed considerable heterogeneity.

Conclusions In spite of the unavailability of sufficient longterm evidence to justify using zirconia oral implants, zirconia ceramics could potentially be the alternative to titanium for a non-metallic implant solution. However, further clinical
\end{abstract}

Dena Hashim

dr.dhashim@gmail.com

1 School of Dental Medicine, Division of Periodontology, University of Geneva, Rue Barthelemy-Menn 19, CH-1205 Geneva, Switzerland

2 University Hospitals of Geneva, Rue Gabrielle-Perret-Gentil 4, CH-1205 Genève, Switzerland studies are required to establish long-term results, and to determine the risk of technical and biological complications. Additional randomized controlled clinical trials examining two-piece zirconia implant systems are also required to assess their survival and success rates in comparison with titanium as well as one-piece zirconia implants.

Clinical relevance Zirconia implants provide a potential alternative to titanium ones. However, clinicians must be aware of the lack of knowledge regarding long-term outcomes and specific reasons for failure.

Keywords Zirconia $\cdot$ Dental implants $\cdot$ Systematic review $\cdot$ Survival

\section{Introduction}

In a world with increasingly heightened esthetic demand, ceramics have become progressively more popular in the dental industry. Nowadays, they are widely used as veneers and abutments for both tooth- and implant-supported all-ceramic restorations, as well as for fabrication of oral implants. Densely sintered alumina $\left(\mathrm{Al}_{2} \mathrm{O}_{3}\right)$ and yttria-stabilized tetragonal zirconia polycrestal ceramics (Y-TZP) are currently the materials of choice for ceramic abutments [1]. Yet, when it comes to oral implants, zirconia has repeatedly been proven superior to other ceramics in terms of bending strength and fracture toughness [2]. Its low modulus of elasticity and thermal conductivity, low affinity to plaque, and high biocompatibility, in addition to its white color, have made zirconia ceramics a very attractive alternative to titanium in implant dentistry [3-6]. Still, when it comes to disadvantages, lowtemperature degradation, also known as ageing, is considered one of zirconia's major drawbacks. It is a process which results in degradation of the mechanical properties due to the 
progressive spontaneous transformation of the metastable tetragonal phase into a monoclinic one at temperatures above $200{ }^{\circ} \mathrm{C}$ in the presence of water vapor. This causes reduction in the strength, toughness and density of the material. However, reduction in grain size and/or increase in the concentration of stabilizing oxides reduce the transformation rate [7]. An additional concern when using zirconia oral implants has been addressed in an in vitro study evaluating fracture strength. The authors established that both preparation and cyclic loading of zirconia implants can reduce their fracture strength resistance. Nevertheless, they reported that even implants with low mean fracture strength can withstand extended intervals of average occlusal loading [8]. In spite of such limitations, animal studies have repeatedly proven zirconia implants to be comparable, if not superior, to titanium implants in terms of biocompatibility and osseointegration [4, 9-14]. A systematic review [12], evaluating the osseointegration and success of zirconia implants in animal studies, revealed a mean bone-to-implant contact (BIC) greater than $60 \%$ in most of the included studies. One even indicated better bone healing on zirconia cones when compared to titanium [15]. Regardless of such auspicious results, the authors could not recommend the use of zirconia dental implants due to the lack of long term clinical results. Another systematic review [2], which included both animal and clinical studies on alumina and zirconia implants, concluded that there was no difference in the rate of osseointegration between the different implant materials in animal studies. Even though alumina implants were not considered a viable alternative to titanium, zirconia, on the other hand, was viewed as a potential successful implant material despite the lack of supporting clinical data. Ever since, multiple studies evaluating the clinical use of zirconia implants have been published. Yet, different studies examined a variety of implant systems with great diversity in implant design, surface modification, surgical and loading protocols, follow-up period, and prosthetic reconstruction. Furthermore, clinical investigations often used variable definitions for implant success with different clinical indexes. Finally, owing to the increasing number of commercially available ceramic implant systems, as well as the increasing demand for non-metallic and highly esthetic restorations, the clinical performance of zirconia implants has become of substantial interest to the dental practitioner. Hence, the aim of this review was to evaluate the clinical success and survival rates of zirconia ceramic implants after at least 1 year of function, and to assess if there is sufficient evidence to justify using them as alternatives to titanium implants.

\section{Materials and methods}

The method used in this systematic review was adapted from the Preferred Reporting Items for Systematic Reviews and
Meta-Analyses (PRISMA) guidelines [16] as well as the recommendations previously established by Needleman [17].

\section{The focused question}

The aim of this review was to answer the following focused questions:

1. What are the clinical survival rates of zirconia ceramic implants?

2. Is there sufficient clinical data on zirconia implants to justify using them as alternatives to titanium implants?

\section{Search strategy}

An electronic search in MEDLINE, EMBASE, and the Cochrane Central Register of Controlled Clinical Trials (CENTRAL) databases was performed for clinical studies published in the English language. No publication year limit was applied so that the search could include the first available year until the first of April 2015. The following search terms (MeSH terms) were utilized: "dental implants" AND ("zirconium oxide" OR "yttria-stabilized tetragonal zirconia polycrystals ceramic"), "dental implants" AND ("zirconia, AND "clinical study"), "dental implants" AND ("zirconium oxide"), "zirconia implants" AND ("clinical" NOT "abutments"), "zirconia implants" AND ("human study" AND "survival rate"), as well as "zirconia implants" AND ("clinical study" AND "failure rate").

\section{Inclusion criteria}

Publications were considered for inclusion if the following criteria were met:

- Studies reported in the English language in dental journals.

- Clinical studies including at least five human subjects with ceramic implant-supported reconstructions.

- All types of zirconia implants including one- and/or two-piece systems.

- Number of implants specified.

- Observation period of at least 1 year after functional loading.

- Survival and/or success rates clearly stated.

- Clear description of the prosthetic reconstruction.

\section{Exclusion criteria}

Studies not meeting all inclusion criteria were excluded from the review. Publications based on charts, questionnaires, or 
interviews were also not considered. Due to the limited number of available studies, no further exclusion criteria were specified.

\section{Selection of studies}

Titles and abstracts derived from the search were independently screened by two authors (DH and NC), based on the listed criteria. Full-text articles were then obtained for all titles agreed upon, and disagreements were resolved by discussion. Cohen's kappa was used to measure inter-reviewer agreement.

\section{Quality assessment}

Assessment of the methodological quality of the included studies was done by the two reviewers (DH and $\mathrm{NC}$ ). The studies where assessed according to their design, extent of clinical and radiographic examinations, adjustment for potential confounding variables and different surgical protocols, completeness of follow-up, and statistical analysis. Industry funding was also taken into consideration. In light of the mentioned criteria, studies were evaluated as having low, moderate, or high risk of bias $[2,18]$.

\section{Data extraction}

Data was extracted on each study's design, publication year, follow-up period, number of patients and implants, implant design and surface characteristics, surgical protocols, survival and/or success rates, details on marginal bone loss (MBL) and prosthetic rehabilitation, as well as failure and complication rates. Any disagreement regarding data extraction was resolved with discussion. If only failure rates were reported, survival rates were calculated after requesting permission from the authors. When data were not clear, the corresponding author was contacted for clarification.

\section{Statistical analysis}

Statistical heterogeneity, assessed using chi-square test and $I^{2}$ statistics, was used to estimate the proportion of variance due to heterogeneity among studies. The prevalence of survival of implants was estimated using the overall proportion reported in the studies with a Clopper-Pearson $95 \%$ confidence interval (random effect model with a Der-Simonian Laird estimate). Forest plots were used to show the prevalence estimated in each study with its confidence interval and the weight given to each study in the meta-analyses, along with the overall pooled prevalence.

\section{Results}

The initial electronic database search yielded 1,519 titles which were independently screened resulting in the consideration of 43 publications. Abstracts were then reviewed and four in vitro or animal studies were further excluded. The remaining 39 studies were reviewed in details resulting in the exclusion of 10 articles which were examining the same groups of patients already included in other publications. This was established after email communication with the authors. Both reviewers agreed on the classification of 36 of the 39 studies, with an estimated kappa of 0.84 . In case of multiple papers evaluating the same patient group, the latest or the most relevant publications were selected, with the exception of Spies et al. [19]. This study evaluated the same group of patients examined in two consecutive publications [20, 21]. In spite of being more recent, the publication of Spies et al. was excluded because it focused on the survival of the prosthetic superstructures that were fabricated using a novel handlayering technique. Sixteen studies were further excluded due to insufficient sample size or short follow-up period. Finally, 14 clinical trials were selected for inclusion in the current review (Fig. 1). Eleven publications examined onepiece implant systems, two evaluated two-piece systems, and one included both one- and two-piece implants. The studies showed variability in implant surface treatment, surgical and loading protocols, prosthetic rehabilitation, and observation period. Hence, meta-analysis was limited to 1 year of functional loading using a random effect model. Only three publications were randomized clinical trials (RCT), whereas the remaining 11 studies were case series with varying designs. Detailed data for the 14 included studies are listed in Table 1.

\section{Excluded studies}

Out of the 39 publications reviewed in details, 25 were excluded from the final analysis (Table 2). The main reasons for exclusion were the following:

- Sample size.

- Observation period of less than 1 year after loading.

- Unclear surgical and/or prosthetic protocol.

- Studies examining the same group of patients.

\section{Quality assessment}

Table 3 shows the list of studies detailing the criteria used for quality assessment. One study [22] was considered highly biased due to unavailability of details on neither clinical nor radiologic examinations, lack of adjustment for different surgical protocols, and lack of statistical analysis. Six 
Fig. 1 The flow chart for the search strategy

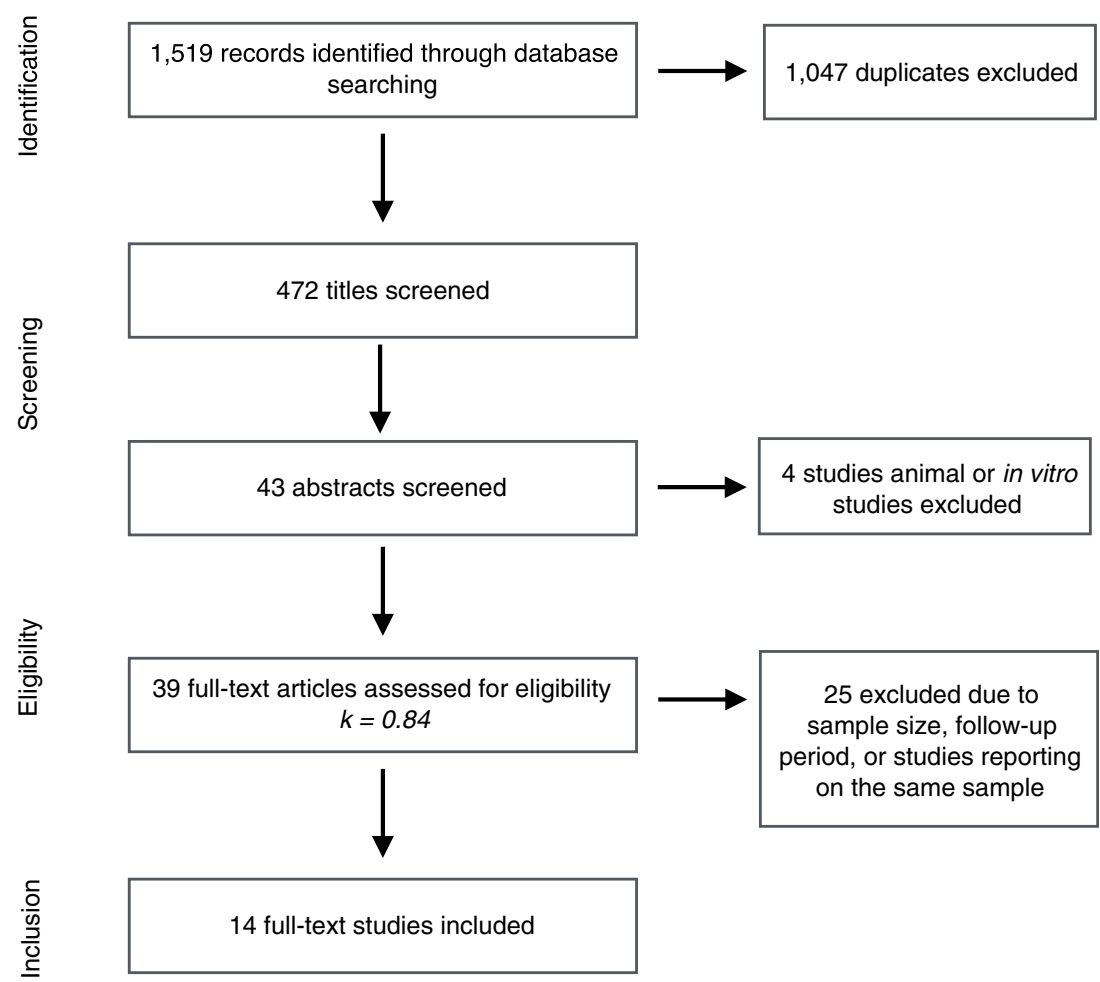

articles [20, 21, 23-26] were considered to have a moderate degree of bias, while the remaining seven [27-33] studies had a low degree of bias.

\section{Assessment of heterogeneity and meta-analysis}

Preliminary examination of the survival of implants at 1 year for the selected studies revealed considerable heterogeneity, $\left(I^{2}=79.3 \%\right.$, tau-squared $\left.=0.698, p<0.0001\right)$. Information on each study's characteristics are detailed in Table 1.

\section{Description of included studies}

\section{One-piece implants}

Eleven studies evaluated one-piece implant systems and one included both one- and two-piece implants. Of these, five investigations examined both immediate and late implant placement, and one did not report the timing of implant surgery.

In the first study [22], 34 patients with 66 zirconia implants were monitored over a period of 2 to 5 years. The fixtures were either splinted or protected with special prostheses during a healing period of 4 to 6 months. However, details regarding timing, surgical protocol, clinical and radiographic examinations were not provided. The authors reported good osseointegration related to $98 \%$ of the implants 1 to 2 years following implantation. Only one implant was fractured due to external trauma, and thereby extracted and subjected to histological evaluation. This revealed direct BIC with neither a fibrous layer nor signs of a foreign body reaction.

Another study [23] evaluated immediate, non-submerged, root-analogue zirconia implants with two different surfaces for single-rooted tooth replacement. Six patients received root-identical replicas with sandblasted implant surfaces, while 12 patients received modified implants with added interdental macro-retention and a slightly reduced bucco-lingual dimension. Implants were inserted 1 to 8 days after tooth extraction by tapping, which resulted in immediate limited functional loading. All six implants in the first group failed prior to prosthetic restoration. The 12 patients in the second group received single composite crowns after a healing period of 3 to 5 months. The overall survival rate of the modified implants was $92 \%$ after $1-33$ months of function. The authors reported excellent esthetic and functional results with minimal bone resorption and soft tissue recession.

A third study [24] evaluated the 5-year success rate of 831 zirconia implants with three different surfaces: uncoated (UC, $n=249$ ), coated (C, $n=249$ ), and acid-etched (ICE, $n=333)$. The UC implants were roughened by mechanical grinding, while the $\mathrm{C}$ implants were roughened and coated with a bioactive ceramic coating composed of $\mathrm{Na}_{2} \mathrm{O}-\mathrm{K}_{2} \mathrm{O}-\mathrm{MgO}-\mathrm{Al}_{2} \mathrm{O}_{3}-\mathrm{CaO}-\mathrm{SiO}_{2}-\mathrm{P}_{2} \mathrm{O}_{5}-\mathrm{F}$, then sintered. This investigation included immediate as well as late implant placement, with or without simultaneous bone augmentation, as well as one- or two-stage sinus lift. Three hundred seventy-eight patients, with a mean follow-up period of 3.4 years, were examined. The 


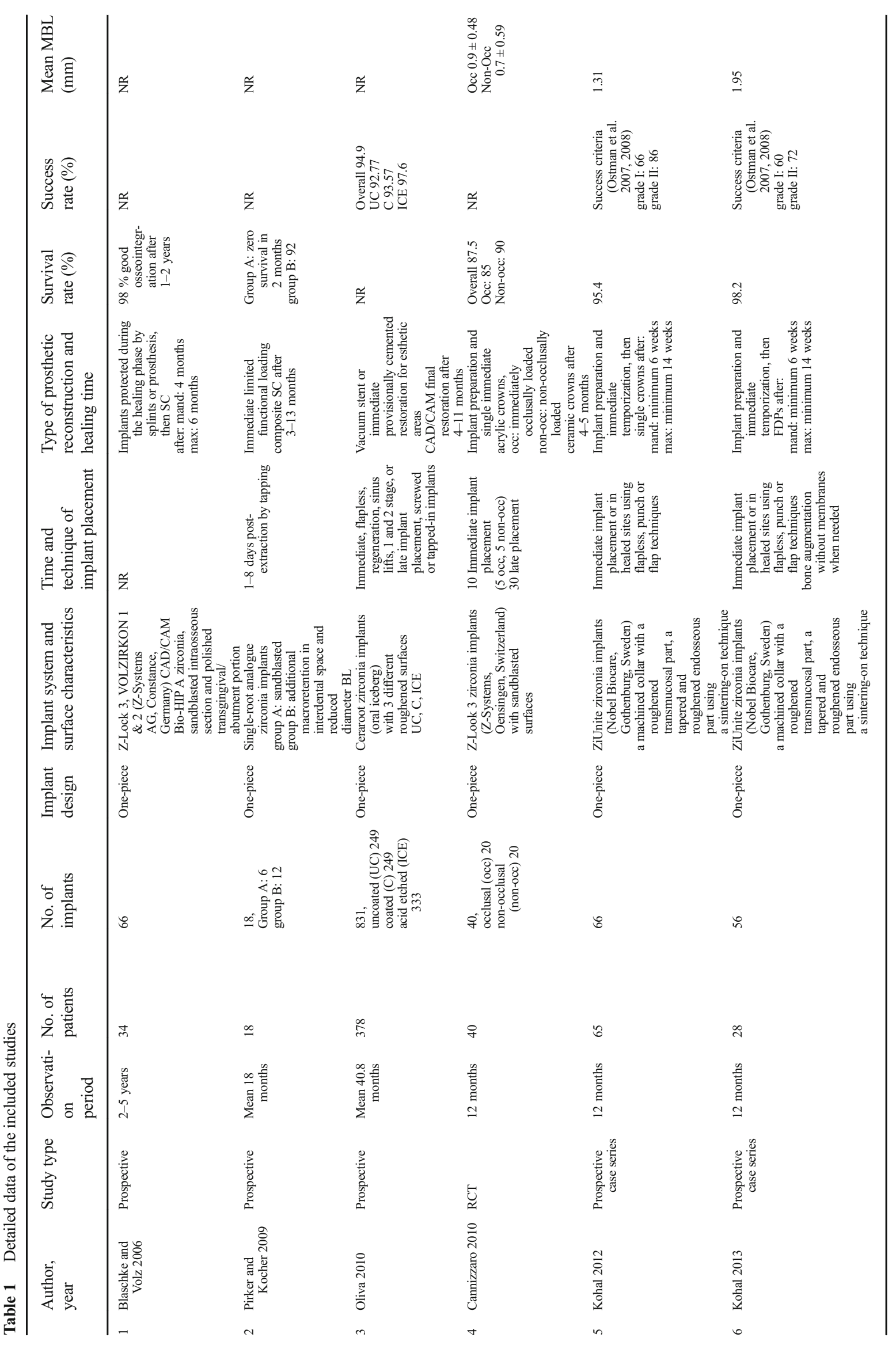




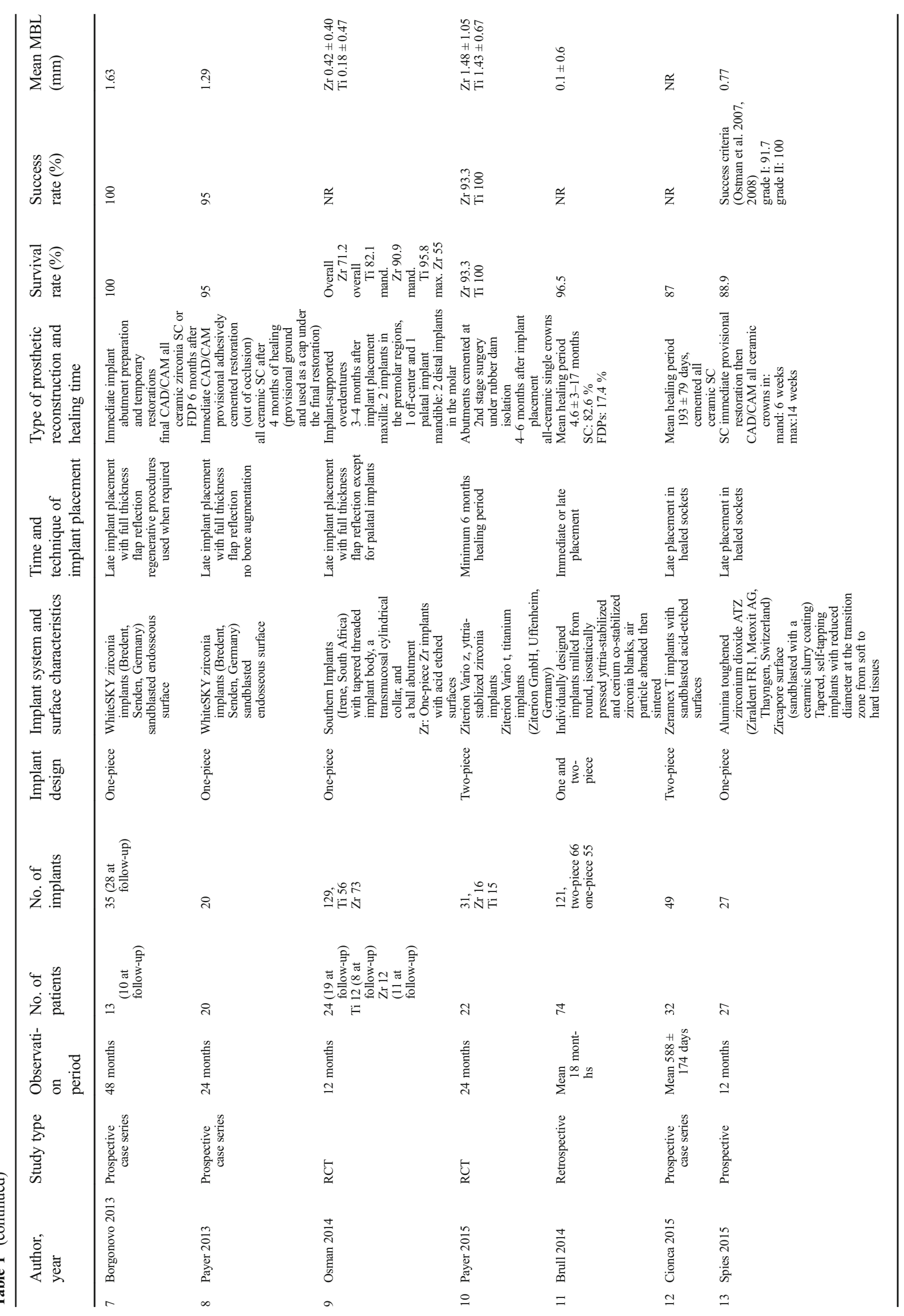




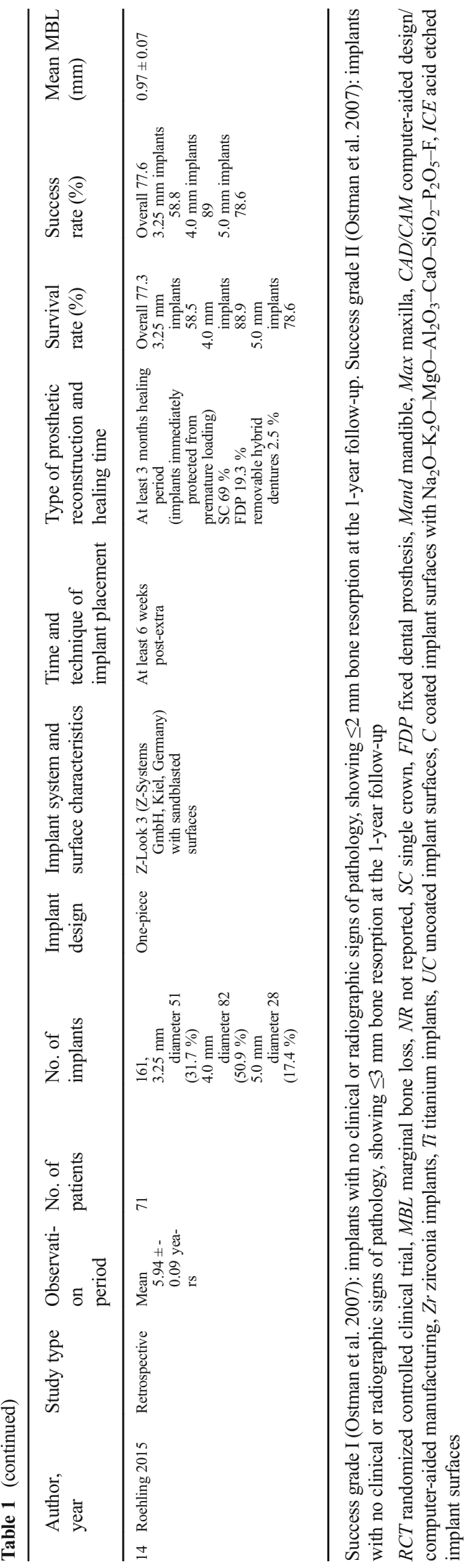

overall 5-year success rate was $95 \%$, with ICE implants showing significantly higher success rate compared to both the $\mathrm{UC}$ and $\mathrm{C}$ ones.

A multi-center randomized controlled clinical trial [27] further compared 20 single non-occlusally loaded zirconia implants with 20 occlusally loaded implants after 1 year of function. Five implants in each group were placed in fresh extraction sockets. Overall, five implants $(12.5 \%)$ failed early; four of which were immediately placed after tooth extraction, and three were occlusally loaded. Both occlusal and non-occlusal implants showed significant marginal bone loss after 1 year of loading, but the difference was not statistically significant between groups. The authors concluded that there was an association between immediate implants and implant failure.

Another group investigated one-piece zirconia implants for single-tooth replacement or 3-unit fixed dental prosthesis (FDP) in two consecutive publications. The first [20] included 65 patients treated with 66 single one-stage implants and immediate temporization. Five implants $(9 \%)$ were placed in fresh extraction sites, 19 (27\%) were placed in healed sites using a flapless technique, and $42(64 \%)$ were placed after flap elevation. Three implants failed early prior to prosthetic restoration leading to a cumulative survival rate of $95.4 \%$ after 1 year. A mean marginal bone loss (MBL) of $1.31 \mathrm{~mm}$ was reported, with 19 implants (34\%) losing at least $2 \mathrm{~mm}$ of bone, and 8 (14\%) losing more than $3 \mathrm{~mm}$ of marginal bone. Yet, stable and healthy peri-implant soft tissue conditions were noted at the 1 year follow-up. Regardless, the authors could not recommend the use of the tested implant system in clinical practice.

The second publication [21] evaluated the 1 year results of 3 -unit FDPs in 28 patients with 56 implants. Five implants (9\%) were immediately placed ( 2 after flap elevation); 51 implants were placed in healed sites (5 using the punch technique and 2 flapless). Only one implant belonging to the immediately placed group failed prior to prosthetic reconstruction, resulting in a survival rate of $98.2 \%$ after 1 year. The mean MBL was $1.95 \mathrm{~mm}$ after 1 year. However, $10 \mathrm{pa}-$ tients $(40 \%)$ showed at least $2 \mathrm{~mm}$ of MBL, while 7 (28\%) lost more than $3 \mathrm{~mm}$, and 3 (12\%) lost more than $4 \mathrm{~mm}$ of marginal bone. A correlation was found between MBL and the flap design. Implants placed using a flapless approach or the punch technique showed significantly more MBL than those placed after flap elevation. Finally, due to the high frequency and increase in radiographic bone loss around the tested implants, the authors concluded that this one-piece zirconia implant system might perform inferiorly to conventional titanium implant systems and to other zirconia implants in terms of MBL.

A 4-year clinical and radiographic study [28] evaluated 13 patients with 35 zirconia implants placed in healed sites. Twenty implants were used for multiple teeth replacement 
Table 2 Excluded studies and reasons for exclusion

\begin{tabular}{|c|c|c|}
\hline & Author, year & Reason for exclusion \\
\hline 1 & Kohal 2004 & Sample size \\
\hline 2 & Oliva 2007 & The same group of patients included in Oliva 2010 \\
\hline 3 & Oliva 2008 & Sample size \\
\hline 4 & Oliva 2008,2 & Sample size \\
\hline 5 & Pirker \& Kocher 2008 & Sample size \\
\hline 6 & Oliva 2010,2 & Sample size \\
\hline 7 & Walker 2010 & Sample size \\
\hline 8 & Borgonovo 2010 & The same group of patients included in Borgonovo 2014 \\
\hline 9 & Arnetzl 2010 & Sample size \\
\hline 10 & Nevins 2011 & Sample size \\
\hline 11 & Pirker 2011 & Sample size \\
\hline 12 & Borgonovo 2011 & The same group of patients included in Borgonovo 2014 \\
\hline 13 & Borgonovo 2012 & The same group of patients included in Borgonovo 2014 \\
\hline 14 & Pirker \& Kocher 2012 & Sample size \\
\hline 15 & Oliva 2012 & Titanium implants with zirconia superstructures \\
\hline 16 & Borgonovo 2013 & The same group of patients included in Borgonovo 2014 \\
\hline 17 & Borgonovo 2013, 2 & The same group of patients included in Borgonovo 2014 \\
\hline 18 & Osman 2013 & Sample size \\
\hline 19 & Gahlert 2013 & The same group of patients included in Roehling 2015 \\
\hline 20 & Aydin 2013 & Sample size \\
\hline 21 & Nair 2013 & Sample size \\
\hline 22 & Bankoglu 2014 & Sample size \\
\hline 23 & Spies 2014 & $\begin{array}{l}\text { The same group of patients included in Kohal 2012, 2013, but this } \\
\text { study evaluated the survival of prosthetic superstructures }\end{array}$ \\
\hline 24 & Siddiqi 2015 & The same group of patients included in Osman 2014 \\
\hline 25 & Gahlert 2015 & Functional loading period less than 1 year \\
\hline
\end{tabular}

while the rest replaced single teeth. However, only 10 patients with 28 implants were available for the final examination. Success and survival rates were calculated at $100 \%$ after 48 months. The mean MBL was $1.631 \mathrm{~mm}$ at the end of the follow-up period, with maxillary implants showing significantly higher MBL during the first year of loading when compared to mandibular ones. In contrast, no differences were found between implants restored with single crowns (SC) or FDPs in terms of MBL. Finally, the authors stated that minimal plaque accumulation, no bleeding, and a probing depth (PD) of $3.19 \mathrm{~mm}$ could be expected around zirconia implant-supported restorations.

Another prospective case series [29] evaluated the outcomes of 20 single-piece, immediately provisionalized, zirconia implants placed in single-tooth gaps after a period of 2 years. The results showed $95 \%$ survival and success rates with a mean MBL of $1.29 \mathrm{~mm}$ at the end of the observation period. Clinical parameters showed healthy soft tissue conditions and an improved, but not significant, pink esthetic score [34] after 24 months. Regardless of such promising results, the authors refrained from drawing final conclusions or clinical recommendations.
One-piece zirconia implants were also evaluated as abutments supporting overdentures, in comparison with titanium implants of similar design [26]. This randomized controlled clinical trial included 24 edentulous patients with 129 implants randomly divided into two groups: the zirconia test group and the titanium control group. Each participant received four maxillary implants distributed in a diamondshaped quad design (one mid-palatal and three anterior crestal), and three mandibular implants with a tripod design (one midsymphyseal and two bilateral distal). There was no significant difference in the survival rate between the groups, but the overall survival rate of $71.2 \%$ was considered low in comparison with other zirconia implant trials. Regarding mandibular implants, the survival rate of the titanium group was $95.8 \%$ compared to $90.9 \%$ for zirconia implants. The maxillary implants' survival rates were 71.9 and $55 \%$ for the titanium and zirconia implants, respectively. Statistical analysis showed a significantly higher risk of failure for maxillary implants. The mean MBL was $0.18 \mathrm{~mm}$ for titanium and $0.42 \mathrm{~mm}$ for zirconia implants for both jaws combined. In contrast to implants placed in the upper arch, significantly higher MBL was found around 
Table 3 Quality assessment of the included studies

\begin{tabular}{|c|c|c|c|c|c|c|c|c|c|c|}
\hline & Study ID & Design & $\begin{array}{l}\text { Evidence } \\
\text { level }^{\mathrm{a}}\end{array}$ & $\begin{array}{l}\text { Detailed } \\
\text { clinical exam }\end{array}$ & $\begin{array}{l}\text { Rx: } \\
\text { quality and } \\
\text { interpretation }\end{array}$ & $\begin{array}{l}\text { Adjustment for } \\
\text { different surgical and } \\
\text { loading protocols }\end{array}$ & $\begin{array}{l}\text { Completeness } \\
\text { of follow-up }\end{array}$ & $\begin{array}{l}\text { Statistical } \\
\text { analysis }\end{array}$ & $\begin{array}{l}\text { Industry } \\
\text { funding }\end{array}$ & $\begin{array}{l}\text { Risk of } \\
\text { bias }\end{array}$ \\
\hline 1 & $\begin{array}{c}\text { Blaschke } \\
2006\end{array}$ & Prospective & III & No & No & No & Yes & No & Yes & High \\
\hline 2 & $\begin{array}{l}\text { Pirker and } \\
\text { Kocher } \\
2009\end{array}$ & Prospective & III & Yes & No & No & Yes & Yes & Unclear & Moderate \\
\hline 3 & $\begin{array}{l}\text { Cannizzaro } \\
2010\end{array}$ & RCT & $\mathrm{Ib}$ & No & Yes & Yes & Yes & Yes & Yes & Low \\
\hline 4 & Oliva 2010 & Prospective & III & No & No & Yes & Yes & Yes & Unclear & Moderate \\
\hline 5 & Kohal 2012 & $\begin{array}{l}\text { Prospective } \\
\quad \text { case series }\end{array}$ & III & Yes & Yes & No & Yes & Yes & Yes & Moderate \\
\hline 6 & Kohal 2013 & $\begin{array}{l}\text { Prospective } \\
\text { case series }\end{array}$ & III & Yes & Yes & No & Yes & Yes & Yes & Moderate \\
\hline 7 & $\begin{array}{l}\text { Borgonovo } \\
2013\end{array}$ & Prospective & III & Yes & Yes & Unclear & Yes & Yes & No & Low \\
\hline 8 & Payer 2013 & $\begin{array}{l}\text { Prospective } \\
\text { case series }\end{array}$ & III & Yes & Yes & Yes & Yes & Yes & Yes & Low \\
\hline 9 & $\begin{array}{r}\text { Osman } \\
2013\end{array}$ & RCT & $\mathrm{Ib}$ & No & Yes & No & Yes & Yes & Unclear & Moderate \\
\hline 10 & Payer 2015 & RCT & $\mathrm{Ib}$ & Yes & Yes & Yes & Yes & Yes & Yes & Low \\
\hline 11 & $\begin{array}{r}\text { Cionca } \\
2015\end{array}$ & $\begin{array}{l}\text { Prospective } \\
\text { case series }\end{array}$ & III & Yes & No & Yes & Yes & Yes & Yes & Low \\
\hline 12 & Brull 2014 & Retrospective & III & Yes & Yes & No & Yes & Yes & Yes & Moderate \\
\hline 13 & Spies 2015 & Prospective & III & Yes & Yes & Yes & Yes & Yes & Yes & Low \\
\hline 14 & $\begin{array}{l}\text { Roehling } \\
2015\end{array}$ & Retrospective & III & Yes & Yes & Yes & Yes & Yes & Yes & Low \\
\hline
\end{tabular}

${ }^{\text {a }}$ According to the definitions of types of evidence originating from the US Agency for Health Care Policy and Research (1993)

zirconia implants placed in the mandible when compared to the titanium group. Moreover, three zirconia implants fractured, two of which were located in the maxillary jaw, resulting in the recommendation of at least four wider diameter fixtures for maxillary overdenture support when using zirconia implants. Further modifications of implant design to improve biomechanics integrity were also recommended. Finally, the authors advised for caution before recommending the use of single-piece zirconia implants for overdenture support.

A more recent prospective investigation [33] was conducted to determine the clinical and radiographic outcomes of onepiece alumina-toughened zirconia implants for single-tooth replacement in 27 patients. Three implants were lost early prior to prosthetic reconstruction. Hence, 24 patients were seen at the 1-year follow-up, resulting in a survival rate of $88.9 \%$. The mean MBL was $0.77 \mathrm{~mm}$ at follow-up, with only two implants $(8.3 \%)$ losing at least $2 \mathrm{~mm}$ of bone. Probing depth (PD) and calculated attachment level (CAL) increased while recession remained stable during the observation period. Mean bleeding ( $\mathrm{mBI}$ ) and plaque ( $\mathrm{mPI}$ ) indexes showed no statistically significant changes within the first year. The authors finally concluded that the tested implant system showed promising short-term results and seemed to be a candidate for clinical use.
Another recent study [32] examined zirconia one-piece implants after up to 7 years of loading. A total of 71 patients with 161 implants and a mean follow-up period of 5.94 years were included in this analysis. The overall survival rate was $77.3 \%$. Implants with reduced diameter $(3.25 \mathrm{~mm})$ showed the lowest survival rate at $58.5 \%$ in comparison with implants of 4.0 and $5.0 \mathrm{~mm}$ diameter at 88.9 and $78.6 \%$, respectively. Fourteen implants were lost prior to prosthetic reconstruction, 4 failed late, and 18 implants were fractured at the coronal part of the sandblasted implant body. The authors concluded that the first-generation zirconia implants investigated showed low overall survival and success rates. They also noted that non-fractured failures were not associated with periimplant infections.

\section{Two-piece implants}

Only two clinical studies evaluating two-piece zirconia implants were included in the current analysis. The first was a prospective study [30] that included 32 patients treated with 49 implants supporting single crowns. The cumulative survival rate was $87 \%$ after 1 year of loading. All failures were due to aseptic loosening. Furthermore, the authors 
reported neither soft tissue complications nor MBL exceeding $2 \mathrm{~mm}$ at the end of the observation period.

The second study was a randomized clinical trial [31] that evaluated 16 zirconia implants in comparison with 15 titanium implants of identical shape in 22 patients. After up to 2 years of loading, the survival rate was 93.3 and $100 \%$ for zirconia and titanium implants, respectively. The mean MBL was $1.48 \mathrm{~mm}$ for zirconia and $1.43 \mathrm{~mm}$ for titanium. The authors further concluded that zirconia implants' survival rate and clinical outcomes showed no significant differences in comparison with titanium implants.

One study [25] retrospectively analyzed the clinical performance of both one and two-piece implants in 74 participants over a period of 3 years. A hundred twentyone implants (55 one-piece and 66 two-piece) were evaluated after a mean observation period of 18 months. The cumulative survival rate of $96.5 \%$ was calculated after 3 years, and the surviving implants showed healthy mucosal conditions with significantly lower bleeding on probing and PD around implants when compared to teeth.

\section{Implant survival}

All but two studies reported cumulative survival rates after at least 1 year of loading. Cannizzaro et al. reported failure rates, which were used for calculation of the survival rate after requesting the author's permission [27]. On the other hand, the 1-year survival rate could not be extrapolated for the study conducted by Bull et al. who reported the 3-year survival rate of both one- and two-piece implants [25]. Therefore, this study was excluded from the quantitative analysis. Only one study reported survival of one-piece implants after 4 years [28], while two others reported the cumulative survival rates after 5 [24] and 7 years [32]. Yet, the meta-analysis was limited to survival of implants at 1 year due to the limited observation period in most studies. The overall survival rate of zirconia one- and two-piece implants was $92 \%$ (95\% CI 87-95) after 1 year of function (Fig. 2).

Table 4 shows the prevalence of early and late failures across the studies, and Fig. 3 shows the forest plot for the early failures of one-piece zirconia implants. However, the meta-analysis was done on one-piece implants excluding Borgonovo et al. who presented data on 28 surviving implants after 4 years of function, and hence, no failures were reported in this publication [28]. Brull et al. [25] was also excluded because they examined both one- and two-piece implants without distinction. Early failure of one-piece zirconia implants ranged between 1.8 [21] and $100 \%$ [23], with the overall early failure rate calculated at $77 \%(95 \%$ CI 56-90). On the other hand, only two $[30,31]$ out of the three studies evaluating two-piece zirconia implants clearly reported failure rates. Cionca et al. reported a failure rate of $12.2 \%$ with only one early failure (2\%) compared to five (10.2\%) late failures [30]. Payer et al. showed a $6.3 \%$ failure rate with only one implant failing after prosthetic rehabilitation [31]. In contrast, Brull et al. only reported the loss of three implants (one early failure, one late failure, and one fractured implant) without details on the implant design [25]. Thus, meta-analysis could not be performed on the early failure of two-piece implants.

\section{Discussion}

This systematic review and meta-analysis focused on clinical studies evaluating the survival rate of zirconia implants after 1 year of function. In contrast to previous reviews, which either evaluated animal studies or were only narrative, only clinical studies with an observation period of at least 1 year were included in this analysis. The overall survival rate of
Fig. 2 Forest plot for the survival of zirconia implants after 1 year of function when all selected studies were included except Brull et al. [25]

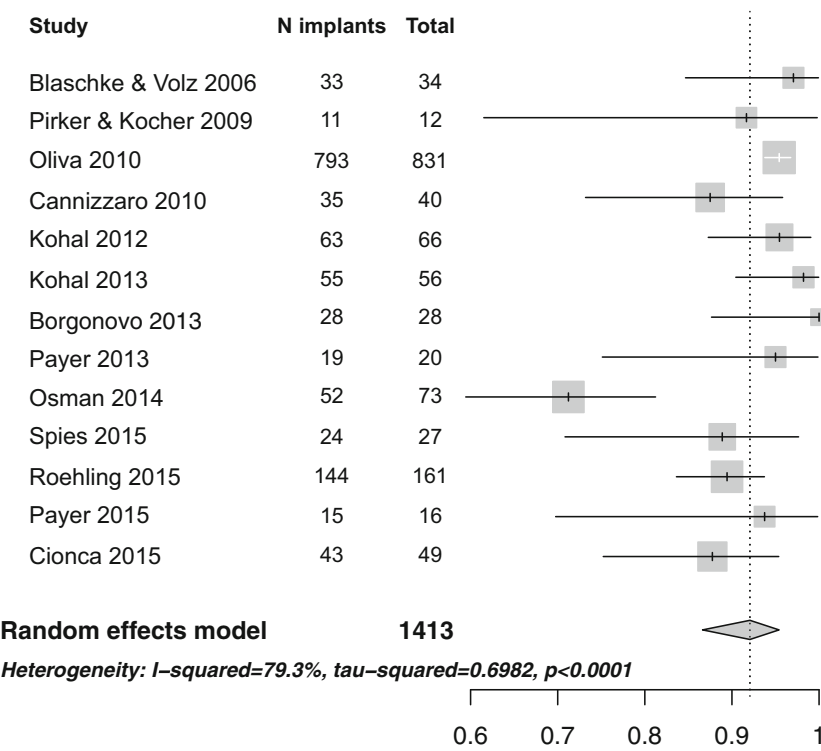


Table 4 Failure rate and the prevalence of early failure, late failure, and implant fracture in the selected studies

\begin{tabular}{|c|c|c|c|c|c|c|}
\hline Author, year & Observation period & $N$ of implants & $\begin{array}{l}\text { Calculated } \\
\text { failure rate }(\%)\end{array}$ & $\begin{array}{l}N \text { of early } \\
\text { failures (\%) }\end{array}$ & $\begin{array}{l}N \text { of late } \\
\text { failures (\%) }\end{array}$ & $\begin{array}{l}N \text { of fractured } \\
\text { implants }(\%)\end{array}$ \\
\hline \multicolumn{7}{|l|}{ One-piece implants } \\
\hline Blaschke and Volz 2006 & $2-5$ years & 34 & 2 & $1(2.9)$ & 0 & $1(2.9)$ \\
\hline \multirow[t]{2}{*}{ Pirker and Kocher 2009} & \multirow[t]{2}{*}{ Mean 18 months } & Group A: 6 & Group A: 100 & Group A: 6 & $(100)$ & 0 \\
\hline & & Group B: 12 & Group B: 8 & Group B: 1 (8.3) & 0 & 0 \\
\hline Oliva 2010 & Mean 40.8 months & 831 & 5.05 & $38(4.6)$ & $4(0.5)$ & 0 \\
\hline Cannizzaro 2010 & 12 months & 40 & 12.5 & 5 (12.5) 3 occlusal, 2 non-occlusal & 0 & 0 \\
\hline Kohal 2012 & 12 months & 66 & 4.6 & $3(4.6)$ & 0 & 0 \\
\hline Kohal 2013 & 12 months & 56 & 1.8 & $1(1.8)$ & 0 & 0 \\
\hline Borgonovo 2013 & 48 months & 28 & 0 & 0 & 0 & 0 \\
\hline Payer 2013 & 24 months & 20 & 5 & $1(5)$ & 0 & 0 \\
\hline Osman 2014 & 12 months & 73 & 28.7 & $15(20.6)$ & $3(4.1)$ & $3(4.1)$ \\
\hline Spies 2015 & 12 months & 27 & 11.1 & $3(11.1)$ & 0 & 0 \\
\hline Roehling 2015 & Mean 5.94 years & 161 & 22.4 & $14(8.7)$ & $4(2.5)$ & $18(11.2)$ \\
\hline \multicolumn{7}{|l|}{ Two-piece implants } \\
\hline Payer 2015 & 24 months & 16 & 6.3 & 0 & $1(6.3)$ & 0 \\
\hline Cionca 2015 & Mean 588 days & 49 & 12.2 & $1(2)$ & $5(10.2)$ & 0 \\
\hline \multicolumn{7}{|c|}{ One and two-piece implants } \\
\hline Brull 2014 & Mean 18 months & 121 & 2.5 & $1(0.8)$ & $1(0.8)$ & $1(0.8)$ \\
\hline
\end{tabular}

zirconia implants was $92 \%$ (95\% CI 87-95) after 1 year of function, with significant heterogeneity between the studies $\left(I^{2}=79.3 \%\right.$, tau-squared $\left.=0.698, \mathrm{p}<0.0001\right)$. In comparison, the overall survival rates of titanium implants supporting single crowns (SC) was $97.2 \%$ at 5 years and $95.2 \%$ at 10 years [35]. While the survival rates of titanium implants supporting fixed dental prosthesis (FDP) was 97.2 and $93.1 \%$ after 5 and 10 years, respectively [36]. Yet, when the prosthetic design is taken into consideration, thereby excluding Osman et al. [26] due to their unconventional prosthetic design, the heterogeneity between the studies decreased to an insignificant level $\left(I^{2}=41.9 \%\right.$, tau-squared $\left.=0.16, p=0.06\right)$. Moreover, the cumulative survival rate for zirconia implants with fixed reconstructions increased to $93 \%(95 \%$ CI 90-95) after 1 year of function (Fig. 4). Osman et al. compared both alveolar and palatal zirconia implants to titanium ones as abutments for overdentures.
The overall survival rate was $71.2 \%$ for zirconia and $82.1 \%$ for titanium implants. This generally low survival was attributed to the implants' one-piece design and their moderately rough surface being in contact with the mucosa, as well as the flapless surgical protocol, the unconventional distribution of the implants, and the immediate loading protocol. Furthermore, their results were affected by the high failure rate of mid-palatal implants (42.1\%), which was believed to be due to either direct trauma from tooth brushing or parafunctional tongue activity.

The survival rates for zirconia implant-supported fixed reconstructions ranged from 87 to $100 \%$. Yet, Cannizzaro et al. [27] who reported a survival of $87.5 \%$ at 1 year evaluated different loading protocols (immediate occlusal or non-occlusal), and 10 out of the 40 implants examined were inserted into fresh extraction sockets. This could account for the lower survival rate of their implants. Moreover, Spies et al. [33], who reported a
Fig. 3 Forest plot for the early failure of zirconia one-piece implants where only the studies evaluating one-piece implants were included with the exception of Borgonovo et al. [28] and Brull et al. [25]

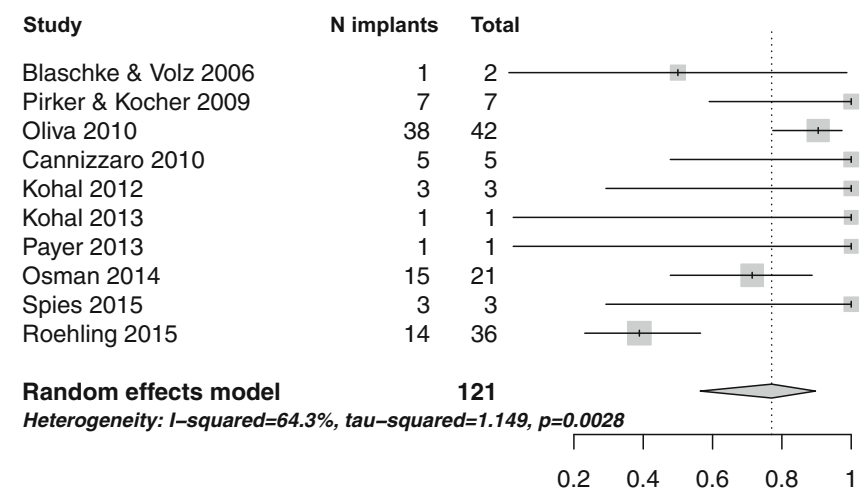

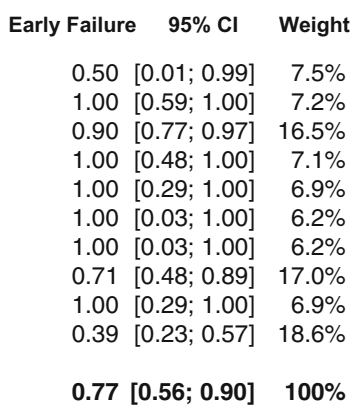


Fig. 4 Forest plot for the survival of zirconia implants after 1 year of function excluding Osman et al. [26] and Brull et al. [25]

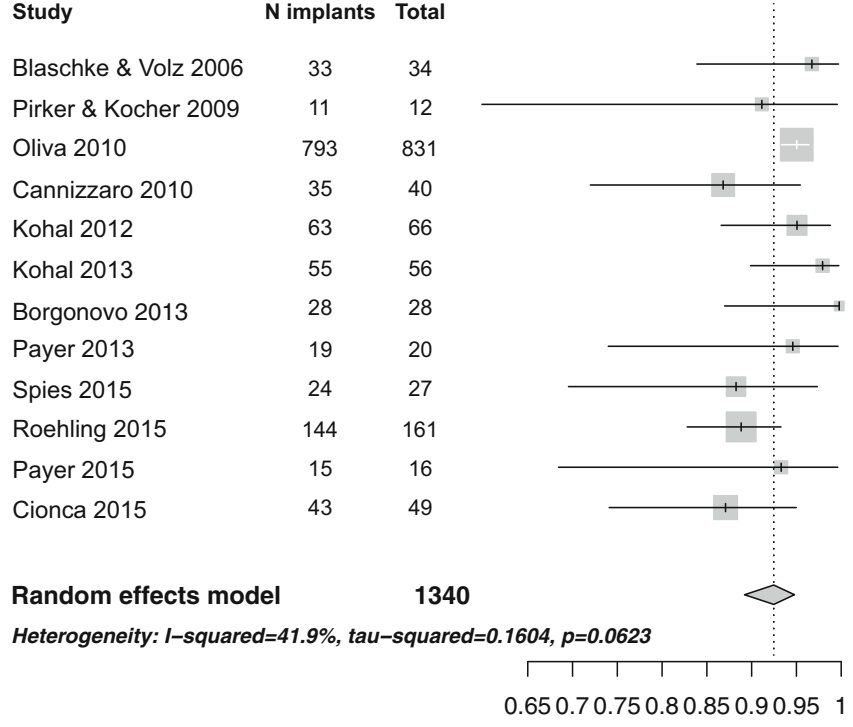

$\begin{array}{ccc}\begin{array}{c}\text { Survival at } 1 \\ \text { year }\end{array} & \mathbf{9 5 \%} \mathbf{C l} & \text { Weight } \\ 0.97 & {[0.85 ; 1.00]} & 3.6 \% \\ 0.92 & {[0.62 ; 1.00]} & 3.4 \% \\ 0.95 & {[0.94 ; 0.97]} & 22.6 \% \\ 0.88 & {[0.73 ; 0.96]} & 10.9 \% \\ 0.95 & {[0.87 ; 0.99]} & 8.3 \% \\ 0.98 & {[0.90 ; 1.00]} & 3.6 \% \\ 1.00 & {[0.88 ; 1.00]} & 1.9 \% \\ 0.95 & {[0.75 ; 1.00]} & 3.5 \% \\ 0.89 & {[0.71 ; 0.98]} & 7.9 \% \\ 0.89 & {[0.84 ; 0.94]} & 18.8 \% \\ 0.94 & {[0.70 ; 1.00]} & 3.5 \% \\ 0.88 & {[0.75 ; 0.95]} & 12.1 \%\end{array}$

$0.93[0.90 ; 0.95] \quad 100 \%$ survival of $88.9 \%$ at 1 year, examined one-piece alumina-toughened zirconia implants. The three implants that failed to osseointegrate were among the first inserted, and their early failure was attributed to the immediate temporization required for one-piece implants and the initial healing period that is highly dependant on the patient's good compliance as well as the clinician's practical values. Cionca et al. [30] further reported a survival rate of $87 \%$ for a two-piece implant system with an acidetched sandblasted surface. In this study, only one implant failed to osseointegrate while five others were lost 1 to 10 months after loading due to aseptic loosening. The implants' experimental design and the type of surface treatment used could have contributed to the lower survival rate when compared to other studies.

When the failure patterns of zirconia implants were examined, one-piece zirconia implants demonstrated a higher tendency towards early failure (Table 4 and Fig. 3), with the overall early failure rate calculated at $77 \%$ (95\% CI 56-90). However, the meta-analysis included a study conducted by Pirker and Kocher which included two types of implants. All six implants in the first group failed early, while only one out of the 12 implants in the second group was lost. Still, the seven reported failures were included in the meta-analysis of the early failure which could have confounded the results [23]. Furthermore, only one study [32] reported a high fracture rate of $11.2 \%$ during a mean observation period of 5.9 years, while three others $[22,25,26]$ reported low implant fracture rates ranging between 0.8 and $4 \%$. Moreover, the single fracture reported by Blaschke et al. was due to external trauma [22]. On the other hand, the two studies examining two-piece implants $[30,31]$ reported a higher percentage of late compared to early failure, and no fractured implants (Table 4). Yet, the significant heterogeneity of the studies and the scarcity of data on two-piece implants hindered statistical analysis.

The results of this analysis should be interpreted with caution for several reasons. First, the majority of the analyzed studies were case reports with limited sample sizes and shortterm follow-up. Second, the selected studies examined zirconia implants with considerable variability in implant design, surface characteristics, surgical protocols, and prosthetic superstructures. Six studies reported on outcomes after immediate implant placement [20, 21, 23-25, 27], which has been proven to have significantly lower survival rates for titanium implants [37]. Furthermore, the heterogeneity between studies regarding the type of implant surface treatment, which significantly affects osseointegration [38-40], could account for the differences in survival rates. Out of the 14 studies included in this investigation, only Oliva et al. compared implants with different surface modifications. They established that acid-etched zirconia implants had significantly higher survival rates $(97.6 \%)$ when compared to the simply roughened uncoated or coated implants, at 92.77 and $93.57 \%$, respectively [24]. Comparison of a certain type of surface treatment across studies could not be done due to the high variability between studies in that respect. However, since none of the studies utilized machined implants, and since multiple studies showed better osseointegration of roughened zirconia implants regardless of the surface treatment used [13, 38, 39, 41-43], pooling the data was considered appropriate. However, combining the data from one- and two-piece implant systems was still considered one of the downsides of this analysis. This was unavoidable due to the scarcity of reports on two-piece zirconia implants. Also, limitations of one-piece implant systems should be taken into consideration. The sparse options for abutment angulation present a major difficulty that could compromise the surgical positioning of the implant. Furthermore, preparation of sub-optimally positioned implants should be avoided due to its adverse effects on the material's physical properties, as well as the lack of data on the long-term stability afterwards. Single-piece implants also require a load-free healing period, which could be challenging due to the 
inevitable immediate forces directed at the supra-mucosal part during mastication or with tongue movement $[6,8,12]$. A review [6] evaluating one-piece zirconia implants showed survival rates ranging between $74 \%$ and $98 \%$ after $12-$ 56 months, with success rates varying between $79.6 \%$ and $91.6 \%$ after $6-12$ months of function. However, a small number of studies with limited observation periods were available for this analysis. Two-piece zirconia implants were introduced to overcome complications associated with one-piece systems, but their development has been hindered by the material's physical properties, and only few clinical studies evaluated the outcomes of zirconia two-piece implants [25, 30, 31, 44]. This sheds light on the urgent need for further studies examining such implants.

An additional drawback to this review was the type of fixed reconstructions evaluated, as all selected studies examined cemented SCs or FDPs. This was attributed to the lack of screw-retained zirconia implant-supported restorations due to the material's physical limitations. However, excess cement presents a frequent and major complication that has been proven to provoke an inflammatory reaction around titanium implants [45, 46]. Yet, incidence of peri-implantitis has never been reported in conjunction with zirconia implants. It remains to be determined whether this is due to the higher biocompatibility of zirconia ceramics or if it is merely due to the lack of studies on the subject. Finally, this analysis did not address the high MBL associated with zirconia implants, which could be the focus of a future review.

\section{Conclusions}

In spite of the unavailability of sufficient long-term evidence to justify using zirconia oral implants, zirconia ceramics could potentially be the alternative to titanium for a non-metallic implant solution. However, further clinical studies are required to establish long-term results, and to determine the risk of technical and biological complications. Finally, additional RCTs examining two-piece zirconia implant systems are required to assess their survival and success rates in comparison with titanium and one-piece zirconia implants.

\section{Compliance with ethical standards}

Conflict of interest The authors declare that they have no conflict of interests.

Funding For this type of study, funding was not required.

Ethical approval For this type of study, ethical approval was not required.

Informed consent For this type of study, formal consent is not required.
Open Access This article is distributed under the terms of the Creative Commons Attribution 4.0 International License (http:// creativecommons.org/licenses/by/4.0/), which permits unrestricted use, distribution, and reproduction in any medium, provided you give appropriate credit to the original author(s) and the source, provide a link to the Creative Commons license, and indicate if changes were made.

\section{References}

1. Kohal RJ, Att W, Bachle M, Butz F (2008) Ceramic abutments and ceramic oral implants. An update. Periodontol 47:224-243. doi:10.1111/j.1600-0757.2007.00243.x

2. Andreiotelli M, Wenz HJ, Kohal RJ (2009) Are ceramic implants a viable alternative to titanium implants? A systematic literature review. Clin Oral Implants Res 20(Suppl 4):32-47. doi:10.1111/j. 1600-0501.2009.01785.x

3. Piconi C, Maccauro G (1999) Zirconia as a ceramic biomaterial. Biomaterials 20:1-25

4. Scarano A, Di Carlo F, Quaranta M, Piattelli A (2003) Bone response to zirconia ceramic implants: an experimental study in rabbits. J Oral Implantol 29:8-12. doi:10.1563/15481336(2003)029<0008:BRTZCI >2.3.CO;2

5. Scarano A, Piattelli M, Caputi S, Favero GA, Piattelli A (2004) Bacterial adhesion on commercially pure titanium and zirconium oxide disks: an in vivo human study. J Periodontol 75:292-296. doi:10.1902/jop.2004.75.2.292

6. Depprich R, Naujoks C, Ommerborn M, Schwarz F, Kubler NR, Handschel J (2014) Current findings regarding zirconia implants. Clin Implant Dent Relat Res J 16:124-137. doi:10.1111/j.17088208.2012.00454.x

7. Osman RB, Swain MV (2015) A critical review of dental implant materials with an emphasis on titanium versus zirconia. Materials 8 : 932-958. doi:10.3390/ma8030932

8. Kohal RJ, Wolkewitz M, Tsakona A (2011) The effects of cyclic loading and preparation on the fracture strength of zirconiumdioxide implants: an in vitro investigation. Clin Oral Implant Res 22:808-814. doi:10.1111/j.1600-0501.2010.02067.x

9. Ichikawa Y, Akagawa Y, Nikai H, Tsuru H (1992) Tissue compatibility and stability of a new zirconia ceramic in vivo. J Prosthet Dent 68:322-326

10. Kohal RJ, Weng D, Bachle M, Strub JR (2004) Loaded custommade zirconia and titanium implants show similar osseointegration: an animal experiment. J Periodontol 75:1262-1268. doi:10.1902/ jop.2004.75.9.1262

11. Depprich R, Zipprich H, Ommerborn M, Mahn E, Lammers L, Handschel J, Naujoks C, Wiesmann HP, Kubler NR, Meyer U (2008) Osseointegration of zirconia implants: an SEM observation of the bone-implant interface. Head Face Med 4:25. doi:10.1186/ 1746-160X-4-25

12. Wenz HJ, Bartsch J, Wolfart S, Kern M (2008) Osseointegration and clinical success of zirconia dental implants: a systematic review. Int J Prosthodont 21:27-36

13. Kohal RJ, Wolkewitz M, Hinze M, Han JS, Bachle M, Butz F (2009) Biomechanical and histological behavior of zirconia implants: an experiment in the rat. Clin Oral Implant Res 20: 333-339. doi:10.1111/j.1600-0501.2008.01656.x

14. Assal PA (2013) The osseointegration of zirconia dental implants. Schweiz Monatsschr Zahnmed 123:644-654

15. Schultze-Mosgau S, Schliephake H, Radespiel-Troger M, Neukam FW (2000) Osseointegration of endodontic endosseous cones: zirconium oxide vs titanium. Oral Surg Oral Med Oral Pathol Oral Radiol Endodontol 89:91-98 
16. Moher D, Liberati A, Tetzlaff J, Altman DG, Group P (2009) Preferred reporting items for systematic reviews and meta-analyses: the PRISMA statement. J Clin Epidemiol 62:1006-1012. doi: 10.1016/j.jclinepi.2009.06.005

17. Needleman IG (2002) A guide to systematic reviews. J Clin Periodontol 29(Suppl 3):6-9, discussion 37-8

18. Esposito M, Coulthard P, Thomsen P, Worthington HV (2005) The role of implant surface modifications, shape and material on the success of osseointegrated dental implants. A Cochrane systematic review. Eur J Prosthodont Restor Dent 13:15-31

19. Spies BC, Stampf S, Kohal RJ (2014) Evaluation of zirconia-based all-ceramic single crowns and fixed dental prosthesis on zirconia implants: 5-year results of a prospective cohort study. Clin Implant Dent Relat Res J. doi:10.1111/cid.12203

20. Kohal RJ, Knauf M, Larsson B, Sahlin H, Butz F (2012) One-piece zirconia oral implants: one-year results from a prospective cohort study. 1. Single tooth replacement. J Clin Periodontol 39:590-597. doi:10.1111/j.1600-051X.2012.01876.x

21. Kohal RJ, Patzelt SB, Butz F, Sahlin H (2013) One-piece zirconia oral implants: one-year results from a prospective case series. 2 . Three-unit fixed dental prosthesis (FDP) reconstruction. J Clin Periodontol 40:553-562. doi:10.1111/jcpe. 12093

22. Blaschke C, Volz U (2006) Soft and hard tissue response to zirconium dioxide dental implants - a clinical study in man. Neuroendocrinol Lett 27(Suppl 1):69-72

23. Pirker W, Kocher A (2009) Immediate, non-submerged, rootanalogue zirconia implants placed into single-rooted extraction sockets: 2-year follow-up of a clinical study. Int J Oral Maxillofac Surg 38:1127-1132. doi:10.1016/j.ijom.2009.07.008

24. Oliva J, Oliva X, Oliva JD (2010) Five-year success rate of 831 consecutively placed Zirconia dental implants in humans: a comparison of three different rough surfaces. Int $\mathrm{J}$ Oral Maxillofac Implants 25:336-344

25. Brull F, van Winkelhoff AJ, Cune MS (2014) Zirconia dental implants: a clinical, radiographic, and microbiologic evaluation up to 3 years. Int J Oral Maxillofac Implants 29:914-920. doi:10. 11607/jomi.3293

26. Osman RB, Swain MV, Atieh M, Ma S, Duncan W (2014) Ceramic implants (Y-TZP): are they a viable alternative to titanium implants for the support of overdentures? A randomized clinical trial. Clin Oral Implant Res 25:1366-1377. doi:10.1111/clr.12272

27. Cannizzaro G, Torchio C, Felice P, Leone M, Esposito M (2010) Immediate occlusal versus non-occlusal loading of single zirconia implants. A multicentre pragmatic randomised clinical trial. Eur J Oral Implantol 3:111-120

28. Borgonovo AE, Censi R, Vavassori V, Dolci M, Calvo-Guirado JL, Delgado Ruiz RA, Maiorana C (2013) Evaluation of the success criteria for zirconia dental implants: a four-year clinical and radiological study. Int J Dent 2013:463073. doi:10.1155/2013/463073

29. Payer M, Arnetzl V, Kirmeier R, Koller M, Arnetzl G, Jakse N (2013) Immediate provisional restoration of single-piece zirconia implants: a prospective case series-results after 24 months of clinical function. Clin Oral Implant Res 24:569-575. doi:10.1111/ j.1600-0501.2012.02425.x

30. Cionca N, Muller N, Mombelli A (2015) Two-piece zirconia implants supporting all-ceramic crowns: a prospective clinical study. Clin Oral Implant Res 26:413-418. doi:10.1111/clr.12370

31. Payer M, Heschl A, Koller M, Arnetzl G, Lorenzoni M, Jakse N (2015) All-ceramic restoration of zirconia two-piece implants - a randomized controlled clinical trial. Clin Oral Implant Res 26:371-376. doi:10.1111/clr.12342

32. Roehling S, Woelfler H, Hicklin S, Kniha H, Gahlert M (2015) A retrospective clinical study with regard to survival and success rates of zirconia implants up to and after 7 years of loading. Clin Implant Dent Relat Res J. doi:10.1111/cid.12323

33. Spies BC, Sperlich M, Fleiner J, Stampf S, Kohal RJ (2015) Alumina reinforced zirconia implants: 1-year results from a prospective cohort investigation. Clin Oral Implant Res. doi: 10.1111/clr. 12560

34. Furhauser R, Florescu D, Benesch T, Haas R, Mailath G, Watzek G (2005) Evaluation of soft tissue around single-tooth implant crowns: the pink esthetic score. Clin Oral Implant Res 16: 639-644. doi:10.1111/j.1600-0501.2005.01193.x

35. Jung RE, Zembic A, Pjetursson BE, Zwahlen M, Thoma DS (2012) Systematic review of the survival rate and the incidence of biological, technical, and aesthetic complications of single crowns on implants reported in longitudinal studies with a mean follow-up of 5 years. Clin Oral Implant Res 23(Suppl 6):2-21. doi:10.1111/j.1600-0501.2012.02547.x

36. Pjetursson BE, Thoma D, Jung R, Zwahlen M, Zembic A (2012) A systematic review of the survival and complication rates of implantsupported fixed dental prostheses (FDPs) after a mean observation period of at least 5 years. Clin Oral Implant Res 23(Suppl 6):22-38. doi:10.1111/j.1600-0501.2012.02546.x

37. Chrcanovic BR, Albrektsson T, Wennerberg A (2015) Dental implants inserted in fresh extraction sockets versus healed sites: a systematic review and meta-analysis. J Dent 43:16-41. doi:10. 1016/j.jdent.2014.11.007

38. Sennerby L, Dasmah A, Larsson B, Iverhed M (2005) Bone tissue responses to surface-modified zirconia implants: a histomorphometric and removal torque study in the rabbit. Clin Implant Dent Relat Res J 7(Suppl 1):S13-S20

39. Gahlert M, Gudehus T, Eichhorn S, Steinhauser E, Kniha H, Erhardt W (2007) Biomechanical and histomorphometric comparison between zirconia implants with varying surface textures and a titanium implant in the maxilla of miniature pigs. Clin Oral Implant Res 18:662-668. doi:10.1111/j.16000501.2007.01401.x

40. Saulacic N, Erdosi R, Bosshardt DD, Gruber R, Buser D (2014) Acid and alkaline etching of sandblasted zirconia implants: a histomorphometric study in miniature pigs. Clin Implant Dent Relat Res J 16:313-322. doi:10.1111/cid.12070

41. Rocchietta I, Fontana F, Addis A, Schupbach P, Simion M (2009) Surface-modified zirconia implants: tissue response in rabbits. Clin Oral Implant Res 20:844-850. doi:10.1111/j.1600-0501.2009.01727.x

42. Setzer B, Bachle M, Metzger MC, Kohal RJ (2009) The geneexpression and phenotypic response of hFOB 1.19 osteoblasts to surface-modified titanium and zirconia. Biomaterials 30:979-990. doi:10.1016/j.biomaterials.2008.10.054

43. Hempel U, Hefti T, Kalbacova M, Wolf-Brandstetter C, Dieter P, Schlottig F (2010) Response of osteoblast-like SAOS-2 cells to zirconia ceramics with different surface topographies. Clin Oral Implant Res 21:174-181. doi:10.1111/j.1600-0501.2009.01797.x

44. Nevins M, Camelo M, Nevins ML, Schupbach P, Kim DM (2011) Pilot clinical and histologic evaluations of a two-piece zirconia implant. Int J Periodont Restor Dent 31:157-163

45. Sailer I, Muhlemann S, Zwahlen M, Hammerle CH, Schneider D (2012) Cemented and screw-retained implant reconstructions: a systematic review of the survival and complication rates. Clin Oral Implant Res 23(Suppl 6):163-201. doi:10.1111/j.1600-0501. 2012.02538.x

46. Wittneben JG, Millen C, Bragger U (2014) Clinical performance of screw- versus cement-retained fixed implant-supported reconstructions - a systematic review. Int J Oral Maxillofac Implants 29(Suppl):84-98. doi:10.11607/jomi.2014suppl.g2.1 


\section{Excluded Studies}

47. Arnetzl GV, Payer M, Koller M, Kirmeier R, Arnetzl C, Jakse N, Holly L, Arnetzl G (2010) All-ceramic immediate restoration of one-piece zirconium dioxide implants. Int J Comput Dent 13:27-41

48. Aydin C, Yilmaz H, Bankoglu M (2013) A single-tooth, two-piece zirconia implant located in the anterior maxilla: a clinical report. J Prosthet Dent 109:70-74

49. Bankoglu Gungor M, Aydin C, Yilmaz H, Gul EB (2014) An overview of zirconia dental implants: basic properties and clinical application of three cases. J Oral Implantol 40:485-494

50. Borgonovo AE, Arnaboldi O, Censi R, Dolci M, Santoro G (2010) Edentulous jaws rehabilitation with yttrium-stabilized zirconium dioxide implants: two years follow-up experience. Minerva Stomatol 59:381-392

51. Borgonovo A, Censi R, Dolci M, Vavassori V, Bianchi A, Maiorana C (2011) Use of endosseous one-piece yttrium-stabilized zirconia dental implants in premolar region: a two-year clinical preliminary report. Minerva Stomatol 60:229-241

52. Borgonovo AE, Fabbri A, Vavassori V, Censi R, Maiorana C (2012) Multiple teeth replacement with endosseous one-piece yttrium-stabilized zirconia dental implants. Med Oral Patol Oral Cir Bucal 17:e981-e987

53. Borgonovo AE, Vavassori V, Censi R, Calvo JL, Re D (2013) Behavior of endosseous one-piece yttrium stabilized zirconia dental implants placed in posterior areas. Minerva Stomatol 62:247-257

54. Borgonovo AE, Corrocher G, Dolci M, Censi R, Vavassori V, Maiorana C (2013) Clinical evaluation of zirconium dental implants placed in esthetic areas: a case series study. Eur J Esthet Dent 8:532-545

55. Gahlert M, Burtscher D, Pfundstein G, Grunert I, Kniha H, Roehling S (2013) Dental zirconia implants up to three years in function: a retrospective clinical study and evaluation of prosthetic restorations and failures. Int $\mathrm{J}$ Oral Maxillofac Implants 28:896-904

56. Gahlert M, Kniha H, Weingart D, Schild S, Gellrich NC, Bormann $\mathrm{KH}$ (2015) A prospective clinical study to evaluate the performance of zirconium dioxide dental implants in single-tooth gaps. Clin Oral Implant Res. doi:10.1111/clr.12598

57. Kohal RJ, Klaus G (2004) A zirconia implant-crown system: a case report. Int J Periodont Restor Dent 24:147

58. Nair A, Prithviraj DR, Regish KM, Prithvi S (2013) Custom milled zirconia implant supporting an ceramic zirconia restoration: a clinical report. Kathmandu Univ Med J 11:328-331

59. Nevins M, Camelo M, Nevins ML, Schupbach P, Kim DM (2011) Pilot clinical and histologic evaluations of a two-piece zirconia implant. Int J Periodont Restor Dent 31:157-163
60. Oliva J, Oliva X, Oliva JD (2007) One-year follow-up of first consecutive 100 zirconia dental implants in humans: a comparison of 2 different rough surfaces. Int J Oral Maxillofac Implants 22:430-435

61. Oliva J, Oliva X, Oliva JD (2008) Zirconia implants and allceramic restorations for the esthetic replacement of the maxillary central incisors. Eur J Esthet Dent 3:174-185

62. Oliva J, Oliva X, Oliva JD (2008) Ovoid zirconia implants: anatomic design for premolar replacement. Int J Periodont Restor Dent 28:609-615

63. Oliva X, Oliva J, Oliva JD (2010) Full-mouth oral rehabilitation in a titanium allergy patient using zirconium oxide dental implants and zirconium oxide restorations. A case report from an ongoing clinical study. Eur J Esthet Dent 5: 190-203

64. Oliva J, Oliva X, Oliva JD (2012) All-on-three delayed implant loading concept for the completely edentulous maxilla and mandible: a retrospective 5-year follow-up study. Int J Oral Maxillofac Implants 27:1584-1592

65. Osman RB, Payne AG, Duncan W, Ma S (2013) Zirconia implants supporting overdentures: a pilot study with novel prosthodontic designs. Int J Prosthodont 26:277-281

66. Pirker W, Kocher A (2008) Immediate, non-submerged, rootanalogue zirconia implant in single tooth replacement. Int J Oral Maxillofac Surg 37:293-295

67. Pirker W, Kocher A (2009) True anatomical zirconia implants for molar replacement: a case report from an ongoing clinical study with a 2-year follow-up. Oral Surg 2:144-148

68. Pirker W, Wiedemann D, Lidauer A, Kocher AA (2011) Immediate, single stage, truly anatomic zirconia implant in lower molar replacement: a case report with 2.5 years follow-up. Int J Oral Maxillofac Surg 40:212-216

69. Siddiqi A, Kieser JA, De Silva RK, Thomson WM, Duncan WJ (2015) Soft and hard tissue response to zirconia versus titanium one-piece implants placed in alveolar and palatal sites: a randomized control trial. Clin Implant Dent Relat Res J 17:483-496

70. Spies BC, Stampf S, Kohal RJ (2014) Evaluation of zirconia-based all-ceramic single crowns and fixed dental prosthesis on zirconia implants: 5-year results of a prospective cohort study. Clin Implant Dent Relat Res J. doi:10. $1111 /$ cid. 12203

71. Walker P, Enkling N, Mericske-Stern R, Kolgeci R, Bassetti R (2014) Immediate implant placement in mandible and prosthetic rehabilitation by means of all-zirconium oxide restorations: case report of a woman with a history of periodontitis. Quintessence Int 45:397-404 